\title{
A silicon straight tube fluid density sensor
}

\author{
M Najmzadeh $^{1}$, S Haasl ${ }^{2}$ and P Enoksson ${ }^{1}$ \\ ${ }^{1}$ Department of Microtechnology and Nanoscience, Chalmers University of Technology, \\ SE-412 96, Gothenburg, Sweden \\ ${ }^{2}$ Imego AB, Arvid Hedvalls Backe 4, SE-411 33, Gothenburg, Sweden \\ E-mail: najmzade@student.chalmers.se
}

Received 2 April 2007, in final form 21 June 2007

Published 20 July 2007

Online at stacks.iop.org/JMM/17/1657

\begin{abstract}
In this paper, a new and simple silicon straight tube is tested as a fluid density sensor. The tube structure has a hexagonal cross section. The fabrication process consists of anisotropic silicon etching and silicon fusion bonding. A tube structure with a length of $2.65 \mathrm{~cm}$ was tested. The sample volume is $9.3 \mu \mathrm{L}$. The first three modes of vibrations were investigated with a laser Doppler vibrometer for air and five liquid mixtures. The fluid density sensitivity of each mode was measured and the average was $-256 \pm$ $6 \mathrm{ppm}\left(\mathrm{kg} \mathrm{m}^{-3}\right)^{-1}$ around the density of water. The density of an unknown fluid can be continuously monitored using this sensor by measuring the resonance frequency of one of the vibration modes and extracting the density from the calibration curves.
\end{abstract}

(Some figures in this article are in colour only in the electronic version)

\section{Introduction}

A resonant densitometer is a sensor for measuring fluid density where a change in density results in a change in the mass loading of the resonator structure and thus a change in the resonance frequency [1].

The first micromachined tube structure used as a fluid density sensor was a free-free double-loop resonating structure [1]. The corners in the structure, however, required corner compensation techniques that complicated the fabrication. Two fixed-free resonating structures have also been presented $[2,3]$. All the structures have shown good liquid density sensitivity which according to theory is a function of the ratio of the cross-sectional area of the tube to the cross-sectional area of the fluid, but they had corners. Corners add an additional pressure drop in the tube system and increase the risk of trapping gas bubbles.

Corner compensation techniques can be used to create convex corners in $\mathrm{KOH}$ etching. These techniques, however, are time-stopped and sensitive to overetching. Overetching causes the tube walls to be thinner at these corners, reducing the burst pressure. Sharp corners are furthermore risk zones for clogging by gas bubbles or particles. Clogged gas bubbles can affect the accuracy of the density sensor by shifting the resonance frequency, reducing the vibration amplitude of the tube and reducing the $Q$-factor due to changes in the moment of inertia, as the gas bubbles move up and down in the liquid when the tube is in resonance [4].

Other techniques like using quartz tuning forks, vibrating microdiaphragms, membranes, cantilevers and using magnetoelastic thin or thick films have been presented [5-10]. The advantages of using tubes lie in the low sample volume and the possibility of continuously monitoring the density of a fluid with high resolution.

In [5], a titanium diaphragm was divided into smaller parts by a $10 \mu \mathrm{m}$ nickel, gold and polymer microstructure to create an array of $10 \mu \mathrm{m}$ wide and 1-3 $\mu \mathrm{m}$ thick microdiaphragms. By placing this array in a liquid bath and detecting the echo of an ultrasonic pulse emitted toward this passive array, the resonance frequency of the diaphragms, depending on parameters such as viscosity and density of the medium, could be measured. The relationship between the density and the resonance frequency was linear for this sensor.

In [6], a piezoelectric unimorph cantilever was made of steel foil partially coated with piezo-electric $\mathrm{PbO} \cdot \mathrm{ZrO}_{2} \cdot \mathrm{TiO}_{2}$ (PZT). The cantilever was clamped at the PZT-coated end, and the non-coated end of the cantilever was immersed in the liquid. The resonance spectra of the cantilever could be obtained using an impedance analyzer. The viscosity and the density of the liquid could be measured simultaneously by observing the measured resonance frequency and the peak width of the phase-angle spectra. 
In [7], the resonance frequency and $Q$-factor of a vibrating silicon plate immersed in a fluid provided a measure of the fluid's density and viscosity, respectively. The plate was excited by placing a permanent magnet beneath it and passing an ac current through a coil on the plate. The plate was fabricated from an SOI wafer with a $20 \mu \mathrm{m}$ thick device layer using a multi-layer lithography process. The maximum inaccuracy in the measurements was $\pm 1.5 \%$ for fluid's density between 0.5 and $1.5 \mathrm{~g} \mathrm{~mL}^{-1}$ and $\pm 10 \%$ for fluid's viscosity between 0.4 and $100 \mathrm{cP}$ showing that the sensor could function accurately in extreme environments over a wide density and viscosity range. The sensor was shown to withstand up to $1500 \mathrm{MPa}$ pressure and $200{ }^{\circ} \mathrm{C}$ temperature, allowing it to be used in the harsh down-hole environment found in oil wells.

In [8], a plate-wave device based on a silicon nitride membrane with piezoelectric $\mathrm{ZnO}$ interdigital transducers was used as a density and viscosity sensor. The membrane acted as a passive acoustic delay line whose properties were affected by placing a drop of liquid in the $6 \mu \mathrm{L}$ well formed by the $\mathrm{KOH}$-etched silicon substrate supporting the membrane. Both the viscous dissipation in the liquid and the mass loading due to the effective mass in the viscous boundary layer cause a wave attenuation in the plate-wave delay line, allowing the density and viscosity of the liquid to be determined.

In [9], a commercially available quartz tuning fork was glued to a PZT rectangular plate and placed in a liquid bath. The resonance frequency of the arms of the fork, which are two cantilevers, was detected by applying an ac driving voltage to the PZT actuator and measuring the amplitude of the voltage, generated in the tuning fork due to the piezoelectric effect, and finding the maximum of the $f-V$ curves. The fork's resonance frequency and its amplitude of vibration decrease for increasing ambient fluid density, because of the damping contribution to its dynamic behavior. By this sensor, the density of non-conductive solutions was measurable by an error in the order of $20 \mathrm{~kg} \mathrm{~m}^{-3}$.

In [10], two magnetoelastic sensors $(30 \mathrm{~mm} \times 3 \mathrm{~mm} \times$ $30 \mu \mathrm{m} \mathrm{Fe}{ }_{40} \mathrm{Ni}_{40} \mathrm{P}_{14} \mathrm{~B}_{6}$ Metglas ${ }^{\mathrm{TM}}$ thick-film sensors, alloy $2826 \mathrm{MB}$ ) with different surface roughness were tested. Two sides of one sensor were covered with a $\mathrm{TiO}_{2}$ layer to make the surface smoother. By immersing the sensor in a liquid bath, liquid was trapped in the surface-roughness features causing an increase of the effective loading mass independent of the viscosity of the fluid. The resonance frequency of each sensor could be detected by applying an external magnetic field and detecting the generated magnetic flux from the mechanically deformed sensors by a pickup coil. The difference between the frequency responses of the two sensors was proportional to the density of the liquid. After finding the density, the viscosity could be evaluated from the data.

In this paper, we present the design of a fixed-fixed straight-tube resonating structure (see figure 1). The sample volume is just $9.3 \mu \mathrm{L}$. The design consists of one resonant element, a straight tube and a silicon frame. Having no corners leads to less flow restriction and less risk of trapping gas bubbles in the sensor. In this sensor, the resonant element is a fixed-fixed resonating tube. The silicon frame supports the tube mechanically and serves as an electrical interface. The frame was glued to an aluminum fixture. This fixture mechanically supports the moving part of the sensor and it

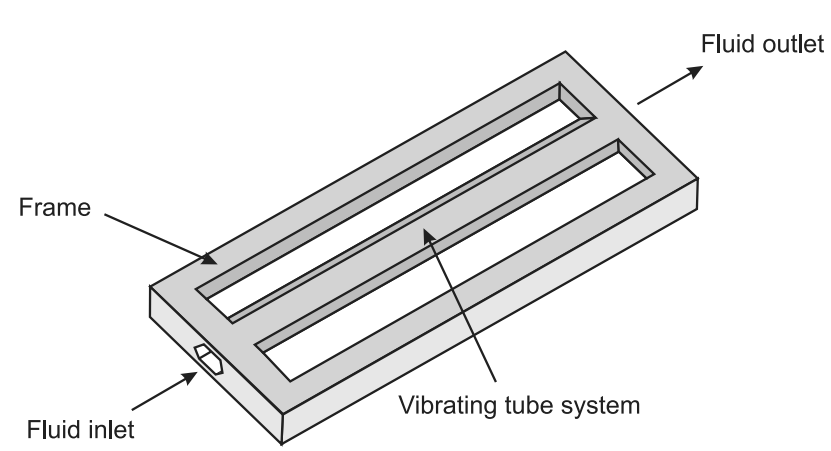

Figure 1. Straight tube densitometer.

allows an external tube system to be connected to the inlet and outlet of the sensor. Electrodes were patterned in an etched recess of a glass slide. The fixture clamps the glass slide close to the vibrating element. The recess depth, and thus the electrode distance, was $6 \mu \mathrm{m}$.

The fabrication consists of etching two silicon wafers in $\mathrm{KOH}$ to produce a pair of half tubes. These two wafers are bonded together by silicon fusion bonding. Another $\mathrm{KOH}$ etching step is used to release the tubes.

In this work, important performance parameters of the densitometer such as the $Q$-factor and the density sensitivity are investigated and calculated for the first three resonance modes of the sensor.

The ability of the sensor to measure the density of multiphase fluids and provide accurate results almost independently of other fluid parameters such as viscosity, allows it to be used varying fields such as the food industry, perfume industry as well as the biomedical, pharmaceutical and petrochemical industries. In the medical field, for example, possible applications of the sensor can be to characterize blood (e.g. hematocrit) or urea. Other applications can be the measurement of alcohol levels or fuel grade monitoring.

\section{Theory}

The resonance frequencies of a clamped-clamped tube can be calculated by [11]

$$
f_{i}=\frac{\lambda_{i}^{2}}{2 \pi L^{2}} \sqrt{\frac{E I}{m}}
$$

where $I$ is the area moment of inertia, $E$ is Young's modulus of $\mathrm{Si}, L$ is the length of the tube and $m$ is the total mass of the resonant element (tube and fluid) per unit length. $\lambda_{i}$ is a constant related to the mode of vibration. For $i=1$ to 3 , it is equal to $4.730,7.853$ and 10.996 , respectively.

$m$, the total mass of fluid and tube per unit length, is equal to

$$
m=\rho_{t} A_{t}+\rho_{f} A_{f} .
$$

By rewriting equation (1) and simplifying all geometric parameters into one constant $C_{i}, f_{i}$ can be written as

$$
f_{i}=C_{i} \sqrt{\frac{E}{\rho_{t} A_{t}+\rho_{f} A_{f}}},
$$

where $C_{i}$ depends on the tube dimensions and the vibration mode. $\rho_{t}$ and $\rho_{f}$ are the densities of the tube and the fluid, 


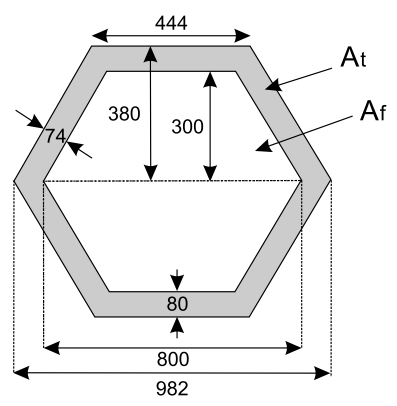

$\mathrm{At}_{\mathrm{t}} / \mathrm{Af}=0.535$

Figure 2. The straight tube design parameters (all the dimensions are in $\mu \mathrm{m})$.

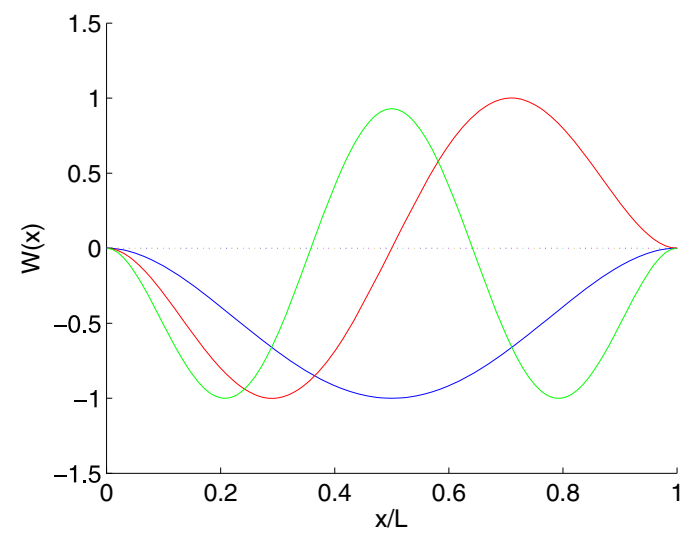

Figure 3. The first three vibration modes of a clamped-clamped beam system. $L$ is the length of the beam and $W(x)$ is the normalized deflection.

respectively. $A_{t}$ and $A_{f}$ are the cross-sectional areas of the tube walls and the fluid.

Fluid density sensitivity for this sensor can be written as

$$
S \equiv \frac{1}{f_{i}} \frac{\partial f_{i}}{\partial \rho_{f}}=-\frac{1}{2\left(\rho_{f}+\frac{A_{t}}{A_{f}} \rho_{t}\right)} .
$$

Therefore, by decreasing $A_{t} / A_{f}$ ratio, the density sensitivity will be increased. The $A_{t} / A_{f}$ design ratio is 0.535 (see figure 2), yielding a theoretical fluid density sensitivity of $-223 \mathrm{ppm}\left(\mathrm{kg} \mathrm{m}^{-3}\right)^{-1}$ at the density of water for each resonance mode (at room temperature and $1 \mathrm{~atm}$ pressure, $\rho_{t}$ and $\rho_{f}$ are equal to 2329 and $997 \mathrm{~kg} \mathrm{~m}^{-3}$, respectively [12]).

Vibration modes were detected using a laser Doppler instrument. Figure 3 shows the first three vibration modes.

Figure 4 shows the theoretical dependence of the first resonance frequency, $f_{1}$, versus the density of the fluid inside the tube.

\section{Design and fabrication}

The main steps of the fabrication process were $\mathrm{KOH}$ etching and silicon-silicon fusion bonding shown in figure 5. In this section, the side on which the wafer is bonded is called the inside side of the wafer.

$75 \mathrm{~mm}(100)$-silicon wafers were thermally oxidized at $1050{ }^{\circ} \mathrm{C}$ in an oven for $25 \mathrm{~min}$ to produce $300 \mathrm{~nm}$ oxide. LPCVD at $770{ }^{\circ} \mathrm{C}$ was used to deposit $100 \mathrm{~nm}$ nitride. After

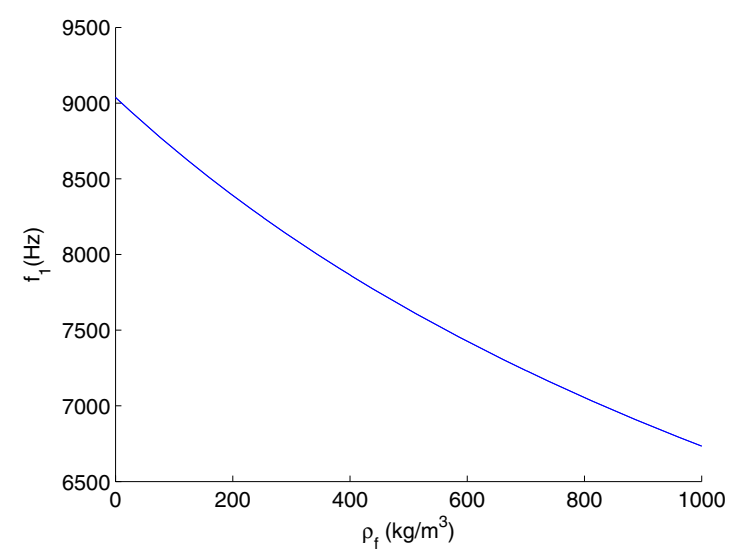

Figure 4. Theoretical dependence of the first resonance frequency versus the fluid's density.

(a)

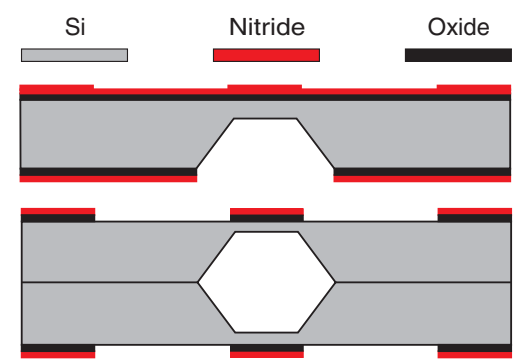

(c)

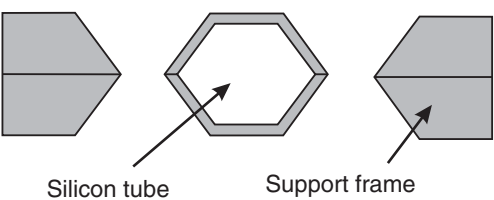

Figure 5. Main steps in the fabrication process.

photolithography, RIE was used to create a nitride mask on the inside side of the wafers. In this step, a Plasma Therm Batchtop PE/RIE $\mathrm{m} / 95$ was used with the following recipepower: $100 \mathrm{~W}$, chamber pressure: $25 \mathrm{mT}$, gas flows: $32 \mathrm{sccm}$ $\mathrm{CF}_{4}, 4 \mathrm{sccm} \mathrm{H}$.

Another photolithography and RIE step was used to create a nitride pattern on the outside mask of the wafers to be able to align two such wafers in the bonding step. $\mathrm{KOH}$ etching was used to create the interior of the tubes (at $80{ }^{\circ} \mathrm{C} ; 35 \mathrm{wt} \%$ $\mathrm{KOH})$.

The pre-bonding process was used to create a hydrophilic and clean silicon surface suitable to bond. Two such wafers were soaked in a Piranha solution (1:3 solution of $\mathrm{H}_{2} \mathrm{O}_{2}$ $37 \mathrm{wt} \%: \mathrm{H}_{2} \mathrm{SO}_{4} 96 \mathrm{wt} \%$ ) for $10 \mathrm{~min}$. A Karl-Suss BA6 bond aligner was used to align the wafers together using alignment marks on the inside and outside sides of the wafers. The aligned wafers were pressed together using a substrate bonder (Karl-Suss SB6) for $5 \mathrm{~min}$ with a force of $7 \mathrm{kN}$ at $50{ }^{\circ} \mathrm{C}$. The pressed wafers were annealed in an oven at $700{ }^{\circ} \mathrm{C}$ for $1 \mathrm{~h}$.

After the silicon-silicon fusion bonding step, $\mathrm{KOH}$ was used to etch the exterior of the tubes to release the structures (at $80{ }^{\circ} \mathrm{C} ; 35 \mathrm{wt} \% \mathrm{KOH}$ ). Finally, the wafer was diced to create $10 \mathrm{~mm} \times 28.5 \mathrm{~mm}$ sensor structures. 


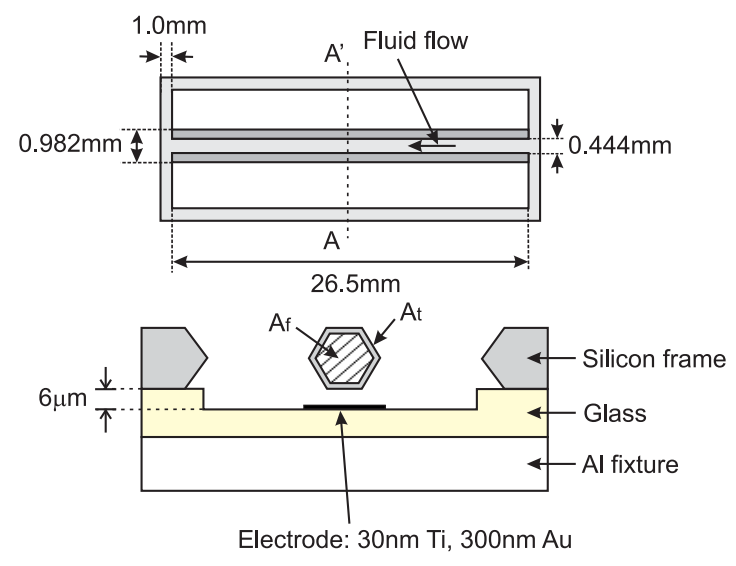

Figure 6. Dimensions of the silicon sensor (top); cross section $\mathrm{A}-\mathrm{A}^{\prime}$ of a glued sensor in the fixture (bottom).

Figure 6 shows the dimensions of the sensor and the cross section of the glued sensor in the fixture.

\section{Measurements}

For evaluation, the sensor was glued to an aluminum fixture using an epoxy glue. The fluid was led to the tube by steel tubes. The electrodes, which are parallel to the resonant tube, are sputtered through a shadow mask in an etched recess of a glass slide. The slide was placed and fixed under the sensor by the fixture. The gap between the electrode and the sensor was $6 \mu \mathrm{m}$. Because of chip bow, the distance between the center of the sensor and the electrode was smaller than the nominal gap. The bow direction was used to assist exciting the tube with a lower amplitude of voltage.

By focusing the laser beam from the laser Doppler head on the resonant tube, the spectrum of vibrations could be detected by the vibrometer (see figure 8 ). Table 2 shows the resonance frequency and the $Q$-factor for each vibration mode for different fluids in the tube, at an ambient pressure of $2 \times 10^{-4}$ mbar. Figure 9 shows a typical spectrum obtained from the LDV. Figure 10 illustrates the typical movements detected by the LDV. To calibrate the densitometer, different mixtures of water and 2-propanol were used to detect the first three resonance frequencies. The density of the tested mixtures was measured using a scale and a volumetric flask. Table 1
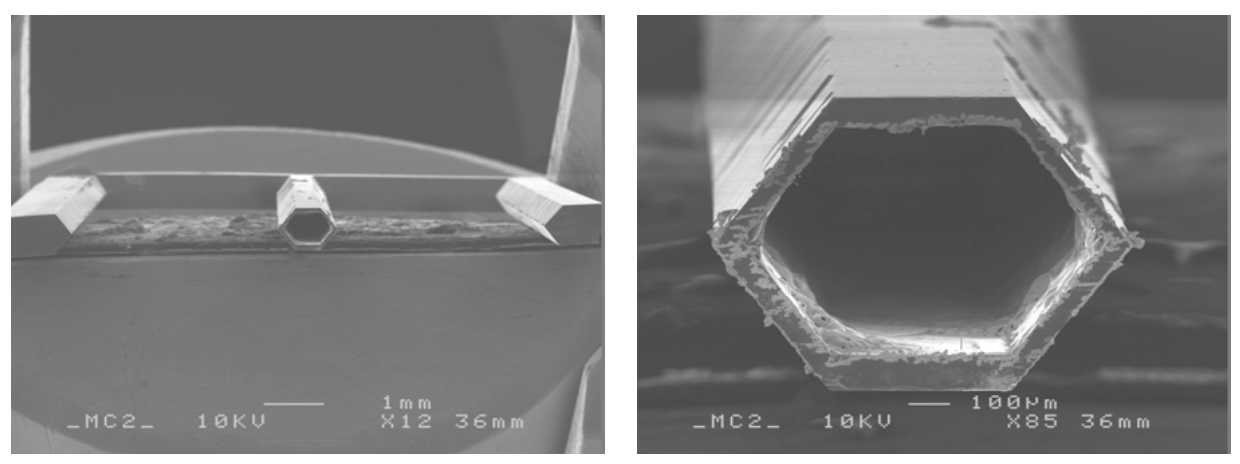

Figure 7. SEM picture of a cross section of a fabricated sensor (not the evaluated tube).

Figure 9. The spectrum of vibrations of a water-filled tube detected by the LDV (average of 30 points along the sensor; using a periodic chirp signal to excite the sensor).

shows the practical evaluation results of changing resonance frequencies with different mixtures of water and 2-propanol (IPA) at $2 \times 10^{-4}$ mbar (frequency resolution: $1 \mathrm{~Hz}$ ).

Figures 11-13 show the change of resonance frequencies with varying liquid density. The regression line related to the least-squares approximation between measurements is drawn in each figure.

In figure 14, the resonance frequencies of an air-filled tube are added to the statistical data and the regression lines are passed through the points using least-squares approximation (chamber pressure: $2 \times 10^{-4}$ mbar; air pressure inside the tube: 1 bar). The calibration curves with more experimental data are being used to do statistical calculations in the discussion.

Figure 8. Evaluating the density sensor by using a laser Doppler vibrometer.

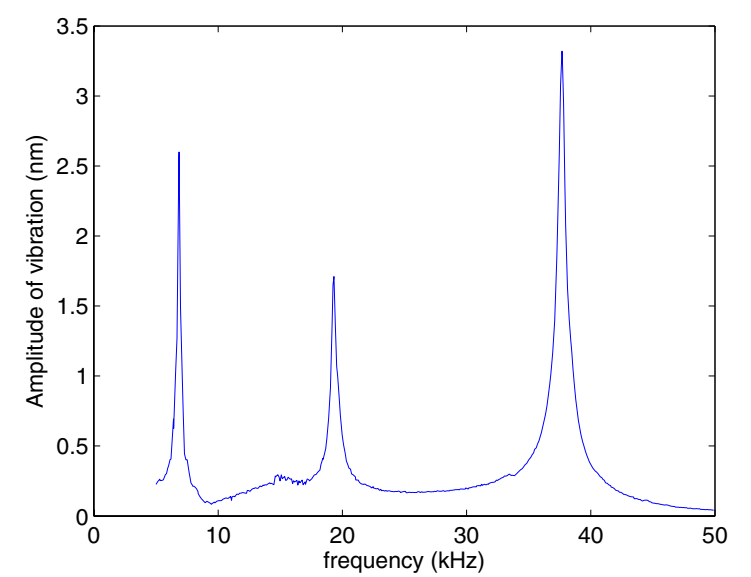




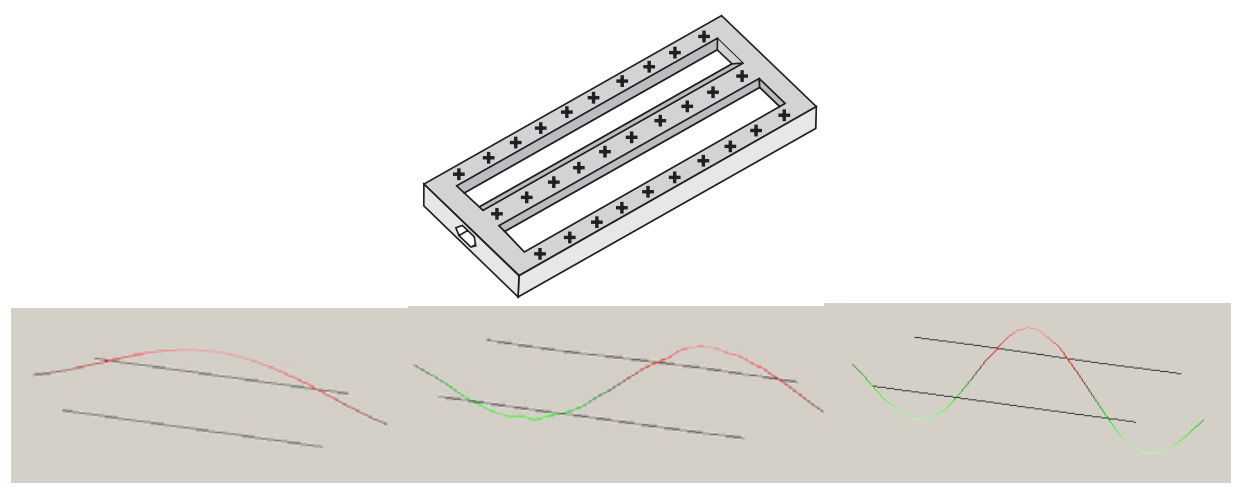

Figure 10. Detected movements of a water-filled tube by the LDV (the measurement points are marked on the sensor).

Table 1. Measurements of the density and the resonance frequencies at a chamber pressure of $2 \times 10^{-4}$ mbar.

\begin{tabular}{lllccl}
\hline$x_{V}(\mathrm{~W})$ & $x_{V}(\mathrm{IPA})$ & $\rho\left(\mathrm{kg} \mathrm{m}^{-3}\right)$ & $f_{1}(\mathrm{~Hz})$ & $f_{2}(\mathrm{~Hz})$ & $f_{3}(\mathrm{~Hz})$ \\
\hline 1.00 & 0.00 & 997.70 & 7127 & 19661 & 38125 \\
0.75 & 0.25 & 958.92 & 7176 & 19822 & 38452 \\
0.50 & 0.50 & 912.19 & 7254 & 20027 & 38800 \\
0.25 & 0.75 & 853.70 & 7381 & 20337 & 39370 \\
0.00 & 1.00 & 779.11 & 7567 & 20847 & 40440 \\
Air & - & 1.2047 & 10104 & 28402 & 54100 \\
\hline
\end{tabular}

$x_{V}(\mathrm{~W})$ : approximate volumetric fraction of water in the mixture. $x_{V}$ (IPA): approximate volumetric fraction of 2-propanol in the mixture.

Table 2. $Q$-factor measurements for different vibration modes of three fluids at a chamber pressure of $2 \times 10^{-4}$ mbar.

\begin{tabular}{lrrr}
\hline Fluid & $Q_{1}$ & $Q_{2}$ & $Q_{3}$ \\
\hline Water & 61 & 72 & 97 \\
2-Propanol & 54 & 70 & 93 \\
Gas* & 138 & 157 & 244 \\
\hline
\end{tabular}

* The pressure inside the tube is equal to the chamber pressure.

\section{Discussion}

\section{1. $Q$-factor}

Table 2 shows that mode 1 has the lowest $Q$-factor. In this mode, the center of mass of the vibrating element moves up and down, causing the frame to vibrate as well. Mode 2 is mass balanced but because of momentum instability, the frame vibrates transversely. In mode 3 , the center of gravity of the vibrating tube goes up and down but it is less than mode 1 . These frame movements, induced by the movement of center of gravity and the momentum instability, together with the observed fact that the frame is stiffer at higher frequencies, can cause the frame loss to be lower at higher mode numbers. This evolution of increasing $Q$-factors with increasing mode shapes, together with the observation that the $Q$-factor is higher for a gas-filled tube than for a liquid-filled (and thus heavier) tube, leads the authors to speculate that the main source of the losses resulting in these limited $Q$-factors is a high loss through the glue used to attach the vibrating element, generally called clamping loss. In comparison with a gas-filled tube, the drop

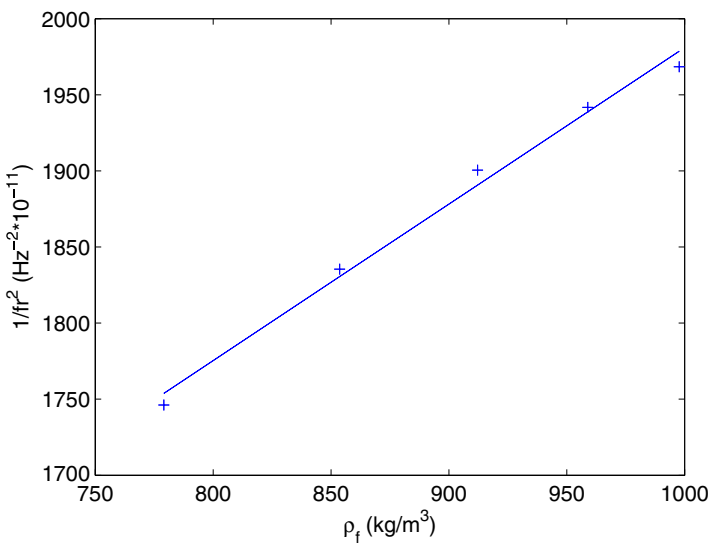

Figure 11. Calibration curve: shift of $f_{1}$ with varying fluid density.

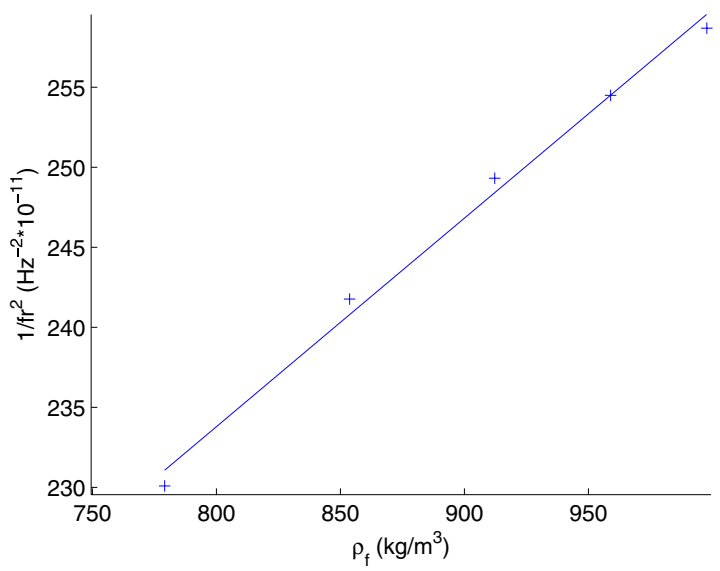

Figure 12. Calibration curve: shift of $f_{2}$ with varying fluid density.

of the $Q$-factor in a liquid-filled tube can also be due to the internal liquid damping that was also observed in encapsulated tube systems [4].

The suggested solution is to use a stiffer glue or to encapsulate the sensor with more rigid methods such as anodic bonding. Prior presented designs were reported to have higher $Q$-factors [1-3, 14]. In [1], this is due to the fact that the double-tube micromachined tube is a free-free resonating system while for $[2,14]$ the size of the single-tube sensor (U-tube [2]) is much smaller than the stiff encapsulation, 


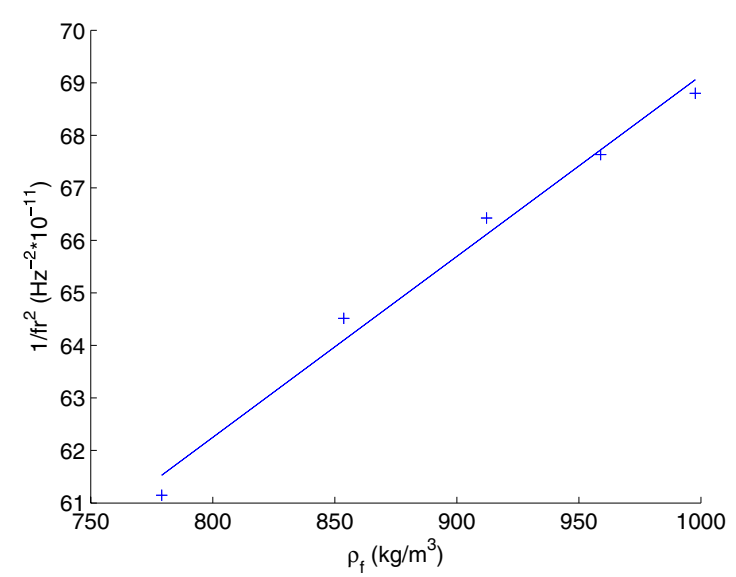

Figure 13. Calibration curve: shift of $f_{3}$ with varying fluid density.

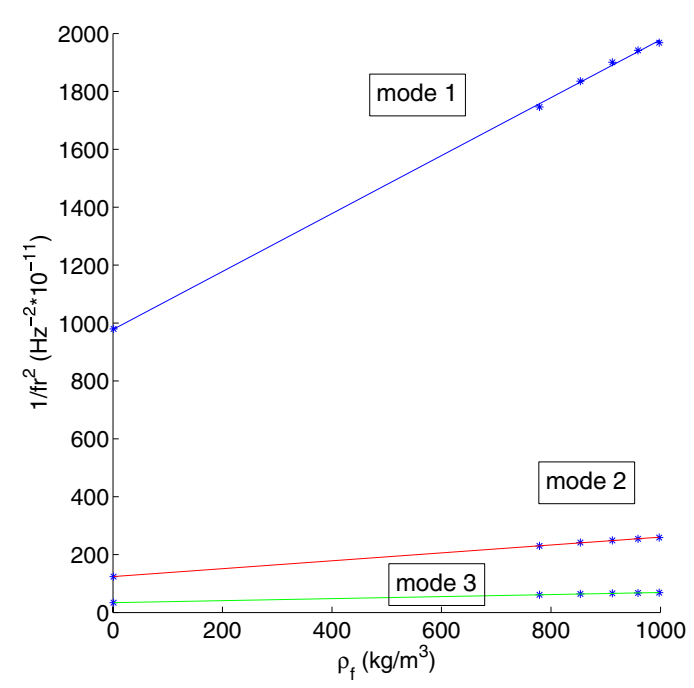

Figure 14. $1 / f_{i}^{2}$ plot of air-filled tube and five different 2-propanol/water mixtures and the relevant regression lines using least-squares approximation.

resulting in less sensitivity to the fixation method. The ease of fabrication of the straight-tube design, together with its increased robustness and reduced bubble trapping risk, however, compensate for this.

At room temperature, the viscosity of 2-propanol is more than twice that of water [13] and the measured $Q$-factors of the water-filled tube and the IPA-filled tube lay within the error margins of the used measurement method. This observation, together with the observed linear calibration curves, indicates that the sensor measures density almost independently of viscosity. A more thorough investigation of the effect of viscosity can be performed by using highly viscous liquids or by improving the $Q$-value by encapsulating the device, reducing clamping losses.

A fluid pressure close to the burst pressure of the tube can slightly expand the tube. Therefore, at high pressures, the resonance frequency of the tube can change due to the change in its cross-sectional ratio. The geometry of a tube like wall thickness and cross-sectional ratio can determine the maximum flow rate for a tube structure. Theoretical calculations show that the burst pressure for this sensor is
Table 3. Comparison of the practical and theoretical values for $B_{i} / B_{j}$ and $A_{i} / A_{j}$.

\begin{tabular}{cccc}
\hline & $A_{i} / A_{j}$ & $B_{i} / B_{j}$ & $\left(\lambda_{j} / \lambda_{i}\right)^{4}$ \\
\hline$i=1, j=2$ & 7.882 & 7.338 & 7.599 \\
$i=1, j=3$ & 28.63 & 28.56 & 29.20 \\
$i=2, j=3$ & 3.632 & 3.893 & 3.843 \\
\hline
\end{tabular}

Table 4. Observed fluid density sensitivity and $A_{t} / A_{f}$ ratio for each vibration mode.

\begin{tabular}{lll}
\hline Mode number & $S\left(\mathrm{ppm}\left(\mathrm{kg} \mathrm{m}^{-3}\right)^{-1}\right)$ & $A_{i} /\left(B_{i} \cdot \rho_{t}\right)$ \\
\hline$i=1$ & -253 & 0.419 \\
$i=2$ & -262 & 0.390 \\
$i=3$ & -254 & 0.418 \\
\hline
\end{tabular}

in the order of $5 \mathrm{MPa}$ corresponding to a maximum flow rate of $35 \mathrm{~g} \mathrm{~s}^{-1}$ for water. However, by ignoring expansion of the tube at high pressures, the resonance frequency of a straight tube is still slightly affected by the flow rate [15]. Theoretical calculations based on theories described in [15] show that for a water-filled tube, by passing the maximum flow rate through the tube, the resonance frequency changes only $0.5 \%$, which is within the margin of error of the resonance frequency measurements. Therefore, at low flow rates, the sensor acts in its linear area and works almost independently of the fluid's pressure and flow rate.

\subsection{Statistical calculations}

For a vibration mode $i$, the equation of the regression line for the measurement results shown in figure 14 can be written as

$$
\frac{1}{f_{i}^{2}}=B_{i} \cdot \rho_{f}+A_{i}
$$

By comparing equation (5) with equations (1) and (3), it can be shown that for modes $i$ and $j$, the fractions of $B_{i} / B_{j}$ and $A_{i} / A_{j}$ should be theoretically equal to $\left(\lambda_{j} / \lambda_{i}\right)^{4}$. Table 3 shows that the practical results of $B_{i} / B_{j}$ and $A_{i} / A_{j}$ for modes 1 to 3 are close to their theoretical calculations validating the theory behind the sensor.

The fluid density sensitivity of each mode for water density is presented in table 4 . The average observed sensitivity equals $-256 \pm 6 \mathrm{ppm}\left(\mathrm{kg} \mathrm{m}^{-3}\right)^{-1}$ for water.

By comparing equation (5) with equation (1) it can be shown that for mode $i$, the actual $A_{t} / A_{f}$ ratio of the tube can be calculated from $A_{i} /\left(B_{i} \cdot \rho_{t}\right)$. Table 4 shows the actual $A_{t} / A_{f}$ ratios of the sensor. Therefore, the average observed ratio is $0.409,24 \%$ smaller than the design ratio (see figure 2), resulting a density sensitivity of $-256 \mathrm{ppm}\left(\mathrm{kg} \mathrm{m}^{-3}\right)^{-1}$ for water. Figure 7 shows that the side walls of the sensor are thinner than designed, resulting in a smaller $A_{t} / A_{f}$ ratio. Alignment inaccuracies, mask underetch during the fabrication process and inaccuracy in the wafer thickness are deemed important causes of the difference between the observed and the theoretical sensitivity values.

\section{Conclusion}

A new sensor for measuring fluid density has been designed, fabricated and tested. The $Q$-factor and the fluid density 
sensitivity for the sensor have been measured for the first three vibration modes. The sensor has an average fluid density sensitivity of $-256 \pm 6 \mathrm{ppm}\left(\mathrm{kg} \mathrm{m}^{-3}\right)^{-1}$ around the density of water. The effect of shifting resonance frequencies of a silicon tube by changing fluid density has been demonstrated. The sensor should be vacuum encapsulated to achieve higher $Q$ values.

\section{Acknowledgments}

The authors thank Henri Jansen, University of Twente, The Netherlands, for his advice on direct wafer bonding.

\section{References}

[1] Enoksson P, Stemme G and Stemme E 1996 Silicon tube structures for a fluid density sensor Sensors Actuators A 54 558-62

[2] Sparks D, Smith R, Straayer M, Cripe J, Schneider R, Chimbayo A, Ansari S and Najafi N 2003 Measurement of density and chemical concentration using a microfluidic chip Lab Chip 319

[3] Westberg D, Paul O, Andersson G I and Baltes H 1997 A CMOS-compatible device for fluid density measurements Micro Electro Mechanical Systems, MEMS '97: Proc. IEEE, 10th Ann. Int. Workshop (26-30 Jan. 1997) pp 278-83

[4] Sparks D, Cruz V and Najafi N 2007 The resonant behavior of silicon tubes under two-phase microfluidic conditions with both microbeads and gas bubbles Sensors Actuators A $135827-32$
[5] Schomburg W K, Vitt M, Bacher W, Borner M W and Menz W 1995 Measurements of physical parameters with ultrasound and microdiaphragms Micro Electro Mechanical Systems, MEMS '95: Proc., IEEE (29 Jan.-2 Feb. 1995) pp 139-44

[6] Shih W Y, Li X, Gu H, Shih W H and Aksay I A 2001 Simultaneous liquid viscosity and density determination with piezoelectric unimorph cantilevers J. Appl. Phys. 891497

[7] Harrison C, Ryu S, Goodwin A, Hsu K, Donzier E, Marty F and Mercier B 2006 A MEMS sensor for the measurement of density-viscosity for oilfield applications Proc. SPIE Int. Soc. Opt. Eng. $611161110 \mathrm{D}$

[8] Martin B A, Wenzel S W and White R M 1989 Viscosity and density sensing with ultrasonic plate waves Sensors Actuators A 22 704-8

[9] Zhang J, Dai C, Su X and O'Shea S J 2002 Determination of liquid density with a low frequency mechanical sensor based on quartz tuning fork Sensors Actuators B 84 123-8

[10] Grimes C A, Kouzoudis D and Mungle C 2000 Simultaneous measurement of liquid density and viscosity using remote query magnetoelastic sensors Rev. Sci. Instrum. 713822

[11] Blevins R D 1979 Formulas for Natural Frequency and Mode Shape (New York: Van Nostrand Reinhold Company)

[12] Lide D R 1999 CRC Handbook of Chemistry and Physics 80th edn (Boca Raton, FL: CRC Press)

[13] Lide D R and Kehiaian H V 1994 CRC Handbook of Thermophysical and Thermochemical Data (Boca Raton, FL: CRC Press)

[14] Sparks D, Trevino J, Massoud-Ansari S and Najafi N 2006 An all-glass chip-scale MEMS package with variable cavity pressure J. Micromech. Microeng. 16 2488-91

[15] Cheesewright R and Clark C 1998 The effect of flow pulsations on Coriolis mass flow meters J. Fluids Struct. 12 1025-40 